\title{
Converting Pirates without Cannibalizing Purchasers: \\ The Impact of Digital Distribution on Physical Sales and Internet Piracy ${ }^{1}$
}

\author{
Brett Danaher, \\ (bdanaher@wharton.upenn.edu) \\ The Wharton School, Uniiversity of Pennsylvania \\ Samita Dhanasobhon, Michael D. Smith, Rahul Telang \\ \{sdhanaso,mds, rtelang\}@andrew.cmu.edu \\ The Heinz College, \\ School of Information Systems and Management
}

forthcoming

Marketing Science

March 2010

1 Author names are in alphabetical order. The authors thank Mel Stephens, Lowell Taylor, Joel Waldfogel, Nitin Mehta, the editors of this journal, and workshop participants at the 2009 NBER Summer Workshop on Information Technology and Economics, the 2009 International Conference on Industrial Organization, the 2008 ZEW Web 2.0 Workshop, the 2008 Workshop on Information Systems and Economics, Arizona State University, the University of California at Irvine, Carnegie Mellon University, Cornell University, the University of Maryland, the University of Southern California, Temple University, the University of Texas at Austin, and the University of Texas at Dallas for valuable comments on this research. We thank Guillermo Jose Aguilar, Temi Awofisayo, Salahaldin Hussein, Suganth Pranesh, and Bryan Springer for excellent research assistance. The authors acknowledge the National Science Foundation for generous financial support provided through CAREER award IIS-0118767 (Smith) and CAREER award CNS-0546009 (Telang). Rahul Telang also acknowledges financial support of Alfred P. Sloan foundation industry studies fellowship. 


\title{
Converting Pirates without Cannibalizing Purchasers:
}

The Impact of Digital Distribution on Physical Sales and Internet Piracy

\begin{abstract}
The availability of digital channels for media distribution has raised many important questions for marketers, notably whether digital distribution channels will cannibalize physical sales and whether legitimate digital distribution channels will dissuade consumers from using (illegitimate) digital piracy channels. We address these two questions using the removal of NBC content from Apple's iTunes store in December 2007, and its restoration in September 2008, as natural shocks to the supply of legitimate digital content, and analyzing the impact of this shock on demand through BitTorrent piracy channels and the Amazon.com DVD store.

To do this we collect two large datasets from Mininova.com and Amazon.com documenting levels of piracy and DVD sales for both NBC and other major networks' content around these events. We analyze this data in a difference-in-difference model and find that NBC's decision to remove its content from iTunes in December 2007 is causally associated with an $11.4 \%$ increase in the demand for NBC's pirated content. This is roughly equivalent to an increase of 48,000 downloads a day for NBC's content and is approximately twice as large as the total legal purchases on iTunes for the same content in the period preceding the removal. We also find evidence of a smaller, and statistically insignificant, decrease in piracy for the same content when it was restored to the iTunes store in September 2008. Finally, we see no change in demand for NBC's DVD content at Amazon.com associated with NBC's closing or reopening of their digital distribution channel on iTunes.
\end{abstract}


"We can't compete with free. That's an economic paradigm that doesn't work."

James Gianopulos, Co-Chairman, Twentieth Century Fox, (quoted in Thompson 2003)

"You'll never stop [piracy]. What you have to do is compete with it."

Steve Jobs, CEO Apple Inc., (quoted in Goodell 2003)

\section{Introduction}

The development of digital distribution channels has raised many important questions for marketers. For television and movie studios two of the more important questions are (1) can paid digital distribution channels serve as an attractive alternative to consumption through ("free") digital piracy channels and (2) will digital distribution cannibalize DVD box set sales?

With respect to the first question, the quote above from James Gianopulos, Co-Chairman of Twentieth Century Fox, is representative of many in the industry who claim that it is difficult, if not impossible, to successfully use paid digital distribution channels to compete with a free (albeit illegal) piracy channel. On the other side of this argument, Steve Jobs, CEO of Apple Incorporated, claims that digital distribution channels, such as Apple's iTunes video store, offer studios the best opportunity to compete with piracy channels by mimicking the ease and convenience of pirated channels at a competitive price point.

With respect to the second question, there is ample evidence in the business press that DVD retailers feel that studios' distribution through digital channels will significantly cannibalize sales of DVDs. For example, in late 2006 after Disney finalized a deal to distribute its movies through iTunes, press reports claim that a Wal-Mart executive visited Hollywood studios to tell them that "it will retaliate against them for selling movies on Apple's iTunes [store]" (Arango 2006). This report goes on to note that Wal-Mart, which makes up an estimated $40 \%$ of studios' DVD sales, made good on this threat by sending "“cases and cases' of DVDs back to Disney." Similarly, 
Target, which makes up an estimated 15\% of DVD sales, sent a letter to studios threatening them not to follow Disney into digital distribution (McBride and Marr 2006), and reportedly after sending this letter "ordered its stores to take down a multitude of internal signs steering customers to Disney products," and replaced Disney's end-cap promotional displays with displays for Disney's competitors (Menn 2006).

However, while these questions have received much discussion in the industry and in the press, we are aware of no empirical studies addressing the degree to which digital distribution of media content impacts demand for physical content and demand for Internet piracy. The goal of this paper is to analyze these questions through a quasi-experiment that occurred on December 1, 2007. During August of 2007 NBC expressed dissatisfaction with the Apple iTunes store's pricing policy. While NBC (and other media companies) wanted more flexibility in pricing, Apple was enforcing a one-price-fits-all policy across nearly all television episodes for sale on iTunes. When negotiations broke down, NBC announced that they would remove all of their content from iTunes on December 1, 2007, a significant move since they reportedly supplied $40 \%$ of all video content on the iTunes store. ${ }^{2}$ In response, Apple refused to offer NBC's fall 2007 season for sale starting in September 2007, and on December 1, 2007 Apple removed all older NBC content from iTunes.

In our analysis, we use this event as an exogenous shock to the legal digital supply of all older seasons of NBC television. This content was generally available for sale on DVD, on iTunes (prior to December 1), and through piracy, and thus we study a market with a physical sales channel, a digital sales channel, and a piracy channel. We account for the possibility of a time trend by comparing changes in piracy and DVD sales two weeks before versus two weeks after

\footnotetext{
${ }^{2}$ Available from http://www.msnbc.msn.com/id/20531069 last accessed October 23, 2009.
} 
December 1 for NBC's competitor networks: ABC, CBS, and Fox (all of which continue to offer their content on iTunes and thus received no shock on December 1). We then contrast this time trend with the change in piracy and Amazon.com DVD sales for NBC, arguing that any differences for NBC content after December 1, over and above the difference for similar television networks, was caused by the removal of NBC content from iTunes. Finally, we ask if our findings are upheld in a second experiment on September 9, 2008, when NBC restored all of their content to the iTunes store.

We find that the removal of NBC content from iTunes caused a $11.4 \%$ increase in piracy for their content, which corresponds to 27 more pirated downloads per day per episode, or about 48,000 total additional pirated downloads per day. This number is nearly twice as large as the daily number of downloads of these episodes on iTunes in the two weeks prior to December 1, implying a fixed cost associated with the decision to pirate: once individuals start to pirate, they pirate more content than they would have originally purchased. This may also imply a spillover effect - that piracy of content on other networks could have increased as a result of NBC's decision to remove their own content from iTunes. While we cannot positively identify this externality due to lack of an appropriate counterfactual, our results are consistent with such an effect as non-NBC piracy increases by $5.8 \%$ over this time period (and thus the documented $11.4 \%$ increase in piracy may understate the true displacement of piracy by digital distribution). Finally, while studying NBC's return to iTunes in September 2008 is complicated by the start of a new season of television, our evidence suggests that the restoration of NBC content to iTunes caused a smaller, statistically insignificant drop in piracy, which is also consistent with a fixed cost to piracy. 
In contrast to the strong correlation between legitimate digital distribution and piracy, we find no change in the Amazon.com sales rank of NBC television season box sets in the four weeks surrounding December 1 relative to the baseline change in non-NBC box sets, implying that while customers who cannot purchase digitally may turn to piracy, they do not consider DVD box sets - at least those sold on Amazon.com — as a substitute to digital downloads.

\section{Literature Review}

As this paper addresses the interaction between legitimate digital and physical distribution channels, and the interaction between legitimate and illegitimate digital distribution channels, the paper fits into two main literatures: the marketing literature studying interactions between various distribution channels, and the economics and information systems literature on online piracy of digital goods.

With respect to the piracy literature, most existing studies examine the effect of online piracy on physical media sales. Most of these studies analyze the impact of piracy on music CD sales, with a few recent studies examining the impact of piracy on movie or television revenue. The challenge in this literature is typically identification, as the correlation between physical sales and pirated downloads of each movie or song is predominantly driven by unobserved heterogeneity across goods.

Papers in this literature address the identification issue in several different ways: through crosscountry variation, exogenous shocks to demand, or through survey results. With respect to crosscountry variation, Zentner (2005), Hui and Png (2003), and Peitz and Waelbroeck (2004) use international panel data on music sales and pirated downloads, with each study finding that piracy displaces CD sales to some extent. Similarly, Danaher and Waldfogel (2008) examine the 
impact of online piracy of Hollywood movies on international box office revenue and find evidence of displacement of ticket sales by online piracy.

In the context of exogenous shocks, one of the tests used by Oberholzer and Strumpf (2004) takes holidays in the German school system as exogenous demand shocks and finds little or no displacement associated with music piracy. Likewise, Smith and Telang (2009) use the television broadcast of a movie as an exogenous demand shock for the DVD and find little or no displacement of DVD sales from piracy for movies broadcast on television.

Finally, in the context of survey data, Rob and Waldfogel (2006) use survey data from a population of college students, asking whether individuals who pirate music purchase less music, including controls such as stated valuations of the albums in question or personal taste for music. Rob and Waldfogel (2007) use a similar approach to study the effect of movie piracy on paid consumption of movies such as theater attendance, DVD rental, and DVD purchase. In both studies the authors find displacement of paid consumption by piracy.

Thus, the majority of existing empirical studies in the literature find some degree of substitution of unpaid "pirated" consumption for paid consumption, ${ }^{3}$ which raises the question of how firms should optimally combat the negative effects of piracy. Recent papers in the literature have examined this question in the context of litigation against pirates, protection of media content through Digital Rights Management (DRM) systems, and purposefully damaging the performance of file sharing networks.

\footnotetext{
${ }^{3}$ We note that many analytic papers have found that piracy need not be harmful to the copyright industries. For example, Jain (2008) argues that piracy need not be harmful to the extent that it may serve as a price discrimination device, allowing price sensitive consumers to pay zero and reducing price competition among other consumers.
} 
Addressing the effectiveness of the first anti-piracy tool, Blackburn (2004) and Bhattacharjee et al. (2008) examine the impact of the RIAA's legal threats against individual file sharers during the summer of 2003 as a quasi-experiment, with both sets of authors finding that when the threat of litigation is higher, file sharing declines but availability of content is still substantial. In the context of DRM protection, Vernik (2009) and Sinha, Machado, and Sellman (2010) argue that the presence of DRM may increase piracy by reducing the usability of the purchased files, causing consumers who otherwise would have purchased to pirate instead. In the context of degrading the performance of file-sharing networks, Christin et al. (2005) study the impact of several different "poisoning" strategies on four popular peer-to-peer file sharing networks and find that the injection of a few replicated decoys can strategically manipulate users' perception of content availability in the network.

However, another important tool that media companies may be able to use to reduce the impact of piracy is directly competing with piracy channels by adding legitimate digital distribution channels. To the best of our knowledge, there are no papers in the literature that examine the interaction between legitimate and illegitimate (piracy) digital distribution channels, and one contribution of this paper is to examine this question.

Our question is also related to the interaction among different distribution channels, which has been widely studied in the marketing literature. For example, Jeuland and Shugan (1983) show that coordination between distribution channels lead to higher profits. Extending this finding, Chiang et al. (2002), Chu et al. (2007), and Webb (2002) develop strategies for firms to manage multiple distribution channels effectively. In the context of direct distribution channels, Balasubramanian (1998) uses analytic models to show that the presence of direct distribution channels, including Internet channels, yields higher returns when the product is well adapted to 
the channel. Other papers in the marketing literature also note that the more differentiated two channels are, the less likely they are to cannibalize one another (e.g., Friedman and Furey (1999) and Viswanathan (2005)).

However, there are relatively few papers in the literature that attempt to directly measure the effect of digital distribution on physical channel sales. One exception is Deleersnyder et al. (2002) which uses a sample of 85 British and Dutch newspapers who added digital distribution channels and finds that when newspapers make their content available online it has only a small impact on physical newspaper sales. Likewise, Biyalogorsky and Naik (2003) find that Tower Records' addition of an Internet distribution channel did not significantly cannibalize their retail sales. With respect to video distribution, Waldfogel (2007) uses survey data to show that authorized Youtube viewing of television content has only a small net displacement effect on over-the-air viewing and may achieve complementarities between the two channels.

In summary, the challenges of identification are significant in this domain. Our paper contributes to the literature by being the first paper we are aware of to use a natural quasi-experiment impacting the supply of legitimate content to address the identification problem. Our paper also contributes to the literature by proposing a technique to collect data documenting piracy levels over time, and by being the first paper we are aware of to empirically estimate how legitimate digital distribution channels interact with demand through both physical and piracy channels.

\section{Theory}

\subsection{Digital Distribution and Piracy}

Theory does not clearly predict the effect of a digital sales channel on consumption in a digital pirate channel. On one hand, iTunes purchases (by far the dominant legitimate digital channel for 
video purchases) and pirated downloads are similar in that both provide high quality, usually fast file downloads that can be viewed on a computer or, with some effort, a television or portable video device. $^{4}$

Given these similarities, one might ask why anyone would purchase through a digital distribution channel if piracy is free. For this to occur, there must be some non-financial cost to piracy. There are several possible categories into which that cost could fit:

i) There may be a cost to learn to use BitTorrent, which would be akin to a fixed cost (especially since BitTorrent is generally considered to be easy to use once learned).

ii) Individuals may experience moral qualms about pirating, which could have the characteristic of a fixed cost (see for example Nagin and Paternoster 1991 in the context of fixed moral costs to committing crimes) or a variable cost.

iii) Individuals may fear being caught and punished, a cost which is also variable with respect to downloads.

iv) It is possible that pirated downloads are viewed as less convenient (and lower quality) as compared to iTunes consumption (either due to the relative ease of use of iTunes versus piracy sites or the variability in quality through piracy sites). This cost would also be variable with respect to the number of downloads.

\footnotetext{
${ }^{4}$ Pirated files, of course, tend to be easier to share or use on a variety of devices (due in large part to the lack of Digital Rights Management restrictions on playback) whereas iTunes downloads tend to have more consistent quality.
} 
Given this, it is straightforward to analyze how the removal of a digital sales channel might impact piracy. Specifically, consider a standard downward sloping demand curve for media downloads and two cases: one where the decision to purchase instead of pirate is driven solely by the high fixed cost of piracy and one where the decision to purchase is driven solely by the high variable costs of piracy.

If the costs to piracy are largely "fixed" in nature and this fixed cost is sufficiently large, then consumers will forgo investing the fixed cost of piracy and purchase a certain quantity of legitimate digital content. However, once the legitimate channel is removed, some consumers will invest the fixed cost associated with piracy and, owing to the lower marginal costs of piracy, will increase their overall level of consumption. On the other hand, if the cost to piracy is variable in nature (i.e. each pirated content imposes a marginal cost) and the marginal cost is constant in the number of pirated episodes, then once the legitimate channel is removed, consumers will decrease their level of consumption of pirated content relative to purchased content.

There are of course other possible structures for the non-financial cost of piracy, including a mix of fixed and variable costs as well as increasing or decreasing marginal cost. ${ }^{5}$ However, even in these environments one can show that when the digital purchase channel is removed, it is possible that an individual would either not turn to piracy, begin to pirate a number of episodes less than or equal to the number of purchases she had been making on iTunes, or even begin pirating more content than she had ever purchased. In short, while due to data limitations we cannot model piracy costs at an individual level, we can use the theory outlined above to infer

\footnotetext{
${ }^{5}$ In fact, it is possible to show that if the marginal cost is increasing then consumers might mix behaviors, pirating some episodes and purchasing others.
} 
the general nature of piracy costs perceived by consumers by observing changes in piracy after iTunes removal. Specifically, an increase in piracy after iTunes removal that is larger than the pre-removal iTunes sales would be consistent with a fixed cost to piracy among a substantial number of users, either through learning or moral costs.

On the other hand, the theory behind the substitutability of iTunes purchases for DVD box sets is less clear than it is for the piracy. It is possible that digital goods cannibalize physical sales. However, unlike the comparison of digital sales to piracy, digital goods don't necessarily have lower profit margins than physical goods do. Moreover, even if digital goods margins are lower, there may be sufficient differentiation between digital and physical goods that they appeal to different customer segments. Finally, even if box sets and file downloads are substitutes for each other, it is possible that individuals who "go digital" will be disinclined to go back to the physical product (indeed, this would be analogous to a fixed cost associated with beginning to download/watch television online).

In summary, iTunes customers may otherwise have been pirates, may otherwise have purchased the box set, or may otherwise not have consumed the content at all. We have shown that it is even theoretically possible that the availability of content on iTunes could displace more pirated downloads than the number of episodes being purchased on iTunes.

Following this analysis, we ask the following two major empirical questions: ${ }^{6}$

i) What happens to the level of piracy of television content when that content is removed from iTunes (and when it is returned)?

\footnotetext{
${ }^{6}$ As we discuss in detail in the data section, it is important to note that of necessity we are asking these questions in relation to older, off-season content for most of our analysis.
} 
ii) What happens to DVD sales of television seasons sold on the Internet when those seasons are removed from the iTunes store?

The answers to (i) and (ii) also provide evidence of the percentage of iTunes purchases that come from otherwise would-be pirates, the possibility that one network's decision to use (or not use) a digital distribution channel can influence piracy of content on other networks, and the shape of the non-financial cost curve associated with piracy.

\section{Data}

To address these questions we use panel data on consumption of pirated television content through major BitTorrent tracker sites, and panel data on sales of DVD season box sets at Amazon.com. We describe these data in more detail below.

\subsection{Piracy Data}

Following Smith and Telang (2009), we use the level of daily downloads of BitTorrent tracker files at Mininova.org as a proxy for piracy activity on the programs in our sample. The website Mininova is a search engine for torrent trackers - the files that allow you to link to other computers and download a specific piece of media content. BitTorrent serves as a useful proxy for video piracy as it was the most popular source of pirated video downloads during our study period (Smith and Telang 2009). Mininova is a useful proxy for download levels through the BitTorrent protocol because it was the most popular BitTorrent tracker site during our study period according to Alexa.com, ${ }^{7}$ it posts a large number of television tracker files, and unlike some other sites it provides information on the cumulative number of downloads for all tracker files downloaded from its site.

${ }^{7}$ Available from http://www.alexa.com/browse?CategoryID=1316737, last accessed April 19, 2009. 
Our piracy dataset contains the daily number of downloads for 5,200 unique episodes of television (corresponding to roughly 75 unique series) starting November 16, 2007. The data include the series name, season number, and episode number of each television program and the number of times that file was downloaded each day. We also added indicators for the network that owns the rights to the show, the genre of the show, and whether it is a series that is still producing new episodes (such as Heroes) or a "catalog” series (such as the original Star Trek).

This dataset was created from a larger dataset we collected monitoring all television trackers posted to Mininova. We collected data at the torrent level starting in November 2007, obtaining roughly 210,000 records per day and yielding dataset of over 68 million observations for 180,000 torrents. We extracted the torrent file names from this dataset and interpreted the file names to code the series, season, and episode for our television data. When a file contains multiple episodes of a television show, we counted this as a download for each episode contained in the file. Because multiple files frequently map to the same episode of television (for example, there may be 6 different torrent files that contain, say, season 1 episode 4 of Grey's Anatomy), we then collapsed the data to the episode level by adding the total daily downloads for an episode across all tracker files mapping to that episode. Repeated observations of the same content over a period of month should minimize any potential measurement errors in our data.

For our analysis, we focus on piracy among television programming for NBC and its subsidiaries (USA and the Sci-Fi Channel). We also analyze piracy for television programming from the other major television networks - $\mathrm{ABC}, \mathrm{CBS}$, and Fox — as a control. We removed all content from the 2007-2008 season from the data because, as noted above, the NBC content being sold 
on iTunes prior to December 1 only included episodes prior to the $2007-2008$ season. ${ }^{8}$ Thus, our analysis compares changes in piracy for older "out-of-season" content.

Finally, in our analysis we focus on the time period two weeks before and two weeks after December 1, 2007 (as well as the two weeks before and after September 9, 2008) in order to best isolate the effect of the removal of NBC content from iTunes on piracy. Our main strategy will be to compare the change in piracy for NBC content after December 1 to the change in piracy for non-NBC content, arguing that any incremental NBC change over and above the non-NBC change is attributable to the removal of NBC content from iTunes.

Importantly, while December 1, 2007 was the official date of NBC's removal from iTunes and December 2 is the first entire day on which the iTunes store held no NBC content, Apple actually began the removal process on November 30 and continued through December 1 . Thus we might expect to see some increase in piracy as early as November 30 , but we conservatively remove December 1 from the data and code December 2 as the first day of the "post removal" period in the data. If, as our data show, piracy began to increase as soon as the removal began, then our selection of this later removal date will lead to an underestimate of the true change in piracy caused by the content's removal from iTunes.

It is also worth noting that past studies on Internet piracy have rarely made use of events or "quasi-experiments," because these events often occur with short notice and data collection on piracy cannot begin soon enough to match the event. Thus a contribution of our study is the method of data collection, which allows us to track a good index of piracy over time and analyze this data when shocks are observed.

\footnotetext{
${ }^{8}$ This is because, starting in August 2008, Apple did not add any new NBC content to the iTunes store in response to NBC's announcement that it would remove all of its content in December.
} 


\subsection{DVD Sales Data}

To analyze the effect of the December 1 experiment on DVD sales, we use a panel data on sales ranks of DVD season box sets on Amazon.com for the same date range: November $18-$ December 15, 2008. We selected Amazon.com as our reference point for changes in DVD sales following the removal of a digital channel because Amazon.com has an estimated $90 \%$ share of online DVD sales in the United States (Netherby 2005) and it seems plausible that users who are no longer able to purchase television content through an Internet channels (i.e., iTunes) would be disproportionately more inclined to purchase DVD box sets from another Internet channel rather than from brick-and-mortar retailers. However, given that Amazon.com is only the fourth largest seller for DVDs in the United States, behind brick-and-mortar retailers Wal-Mart, Target, and Best Buy (DVD News 2006), a conservative interpretation of our results is that they apply only to consumption through Internet DVD channels.

To analyze changes in DVD sales at Amazon.com, we collect daily observations of the price and sales rank for each DVD Amazon sells. We then focus on DVD box sets of television content for the four major networks, capturing the television series, season, and network names.

We interpret the sales rank based on prior work, ${ }^{9}$ which has shown that the relationship between sales rank and sales follows a Pareto distribution:

$$
\text { Quantity }=\alpha \operatorname{Rank}^{\beta}
$$

Thus, following the experiment proposed by Chevalier and Goolsbee (2003), one can estimate the parameters of the relationship between Amazon.com sales rank and actual sales of the product. However, for the purpose of this study, we simply note that this implies that the

\footnotetext{
${ }^{9}$ Chevalier and Goolsbee (2003); Brynjolfsson, Hu, Smith (2003); Ghose, Smith and Telang (2006)
} 
relationship between price and sales rank is best modeled as an elasticity. Prior research ${ }^{10}$ has dealt with the non-linear relationship between Amazon sales and Amazon sales rank by analyzing the effect of events or explanatory variables on the log of sales rank. If an effect is found, the experimental approach can allow us to translate the coefficient into the actual effect on sales, but this turns out to be unnecessary here as we find no statistical effect.

As in our analysis of piracy, we will compare the change in sales rank of NBC season box sets after December 1 to the change in sales rank of $\mathrm{ABC}, \mathrm{CBS}$, and Fox season box sets in order to determine the effect of the removal of NBC's digital distribution channel.

\subsection{Summary Statistics:}

The simplest possible analysis of this quasi-experiment is a comparison of means before and after the removal of NBC content from iTunes on December 1. So to start, we list some very high-level summary statistics and ask if the average number of daily downloads of an NBC episode is greater in the two weeks after December 1 than in the two weeks before. We also test the hypothesis of whether more unique NBC episodes become available through piracy when NBC content is removed from iTunes. Table 1 displays these summary statistics.

Table 1: Piracy Data Summary Statistics November 18 - December 15, 2007

\begin{tabular}{|c|c|c|}
\hline & NBC Networks & Non-NBC Networks \\
\hline 1. Mean daily downloads before $12 / 1$ (balanced panel) & 237 & 405 \\
\hline 2. Mean daily downloads after $12 / 1$ (balanced panel) & 265 & 397 \\
\hline 3. Change & 28 & -8 \\
\hline 4. Number of unique episodes available before $12 / 1$ & 1,683 & 3,400 \\
\hline 5. Number of unique episodes available after 12/1 & 1,812 & 3,383 \\
\hline 6. Change & 129 & -17 \\
\hline
\end{tabular}

\footnotetext{
${ }^{10}$ Smith and Telang (2008)
} 
In rows 1, 2, and 3, we report the mean download statistics for NBC and non-NBC shows. During our study period, the average number of daily downloads for NBC episodes increased by 28 while the average for non-NBC shows decreased slightly. Thus, it provides a basic trend for our results that $\mathrm{NBC}$ downloads have increased compared to the control panel. We use a balanced panel to construct these statistics and in our subsequent regressions: i.e. we only use episodes that were available both before and after the event. If a new episode appears then it is a supply side shift and we ignore it to avoid the bias in the demand side shift. This approach is conservative as ignoring new episodes made available on piracy after the removal of NBC content from iTunes should, if anything, introduce additional competition for interest among the other episodes in our sample.

In rows 4,5 , and 6 , we outline the supply sides of the effect of content removal from iTunes. In the two weeks after December 1 there were a net 129 more unique NBC episodes available for piracy than in the previous two weeks. A more detailed analysis shows that 147 new episodes of NBC television became available through pirated channels in the two weeks after December 1, and 18 episodes ceased to be available. In contrast, for non-NBC content, we don't observe any new episodes becoming available, and we observe 17 episodes ceasing to be available. The number of new NBC episodes is striking, since we would expect older content to simply become less popular (and as a result less available) over time.

Examining the newly available episodes, we discover that entire seasons of some less popular NBC content — seasons that were not available on Mininova before December 1 but were available on iTunes — become available on Mininova after December 1. These series include, for example, a number of seasons of Saved by the Bell and Xena: Warrior Princess. None of these seasons had new or updated box sets released or new syndication deals during the time 
period of the study, supporting the inference of causality with NBC's removal from iTunes. In short, it is striking that these entire seasons of older NBC television became available for piracy immediately after the removal of the iTunes channel while no new non-NBC content becomes available. We conjecture that increased demand for these shows through piracy allowed a sufficiently large piracy swarm to exist after the content was no longer available on iTunes.

However, these simple statistics only tell a partial story as they do not control for important episode-level heterogeneity, nor do they reflect an appropriate model of the actual relationship between digital distribution and piracy. Thus, we turn to regression models for our main empirical analysis.

\section{Results}

\subsection{Impact on NBC Piracy}

First, we provide evidence in support of our identifying assumption, that non-NBC piracy is a good counterfactual for NBC piracy. As evidence, we test whether non-NBC piracy and NBC piracy have similar time trends before NBC content is removed from iTunes. Since the raw data in itself is very noisy, we provide a statistical test and then provide a plot of the fitted values to outline the trends in piracy. We utilize a longer time-frame (from Nov 15 to December 24) for the plot. We first estimate the following difference-in-difference model: ${ }^{11}$

$$
\log \left(\text { downloads }_{i t}\right)=\alpha_{i}+\sum_{t=N o v 15}^{\text {Dec } 24} \beta_{t} D_{t}+\sum_{t=N o v 15}^{\text {Dec } 24} \gamma_{t} D_{t} * N B C_{i}+\varepsilon_{i t}
$$

where $N B C_{i}$ is an indicator variable equal to 1 if episode $i$ is broadcast on NBC, $D_{t}$ is a vector of date fixed effects for each day (from November 15, the first date in our data through

\footnotetext{
${ }^{11}$ Note that we do not include a main effect in this equation for the NBC dummy. This effect cannot be identified, as it would be subsumed entirely by the episode fixed effects.
} 
December 24), $\alpha_{i}$ is a vector of episode level fixed effects, Downloads $s_{i t}$ is the total number of pirated downloads of episode $i$ on day $t$, and $\gamma_{\mathrm{t}}$ captures the differences in NBC piracy over the non-NBC piracy on any day $t$. If non-NBC episodes are a good control for NBC episodes then we would expect to $\gamma_{t}$ be zero for dates before the event. Thus we test if $\gamma_{t}=0$ for all $t$ from Nov 15 to Nov $30^{\text {th }}$. Second, assuming that non-NBC piracy is an adequate control, it allows us to visually analyze what happens to NBC piracy relative to non-NBC piracy in the period after removal.

We plot the resulting coefficients in Figure 1 where non-NBC piracy levels are given by $\overline{\mu_{j}}+\beta_{t}$ and NBC piracy levels are given by $\bar{\mu}_{i}+\beta_{t}+\gamma_{t}$ where $\bar{\mu}_{j}$ and $\bar{\mu}_{i}$ are the average baseline piracy for non-NBC and NBC episodes respectively.

Figure 1: NBC vs. Non-NBC Piracy Surrounding December 1, 2007

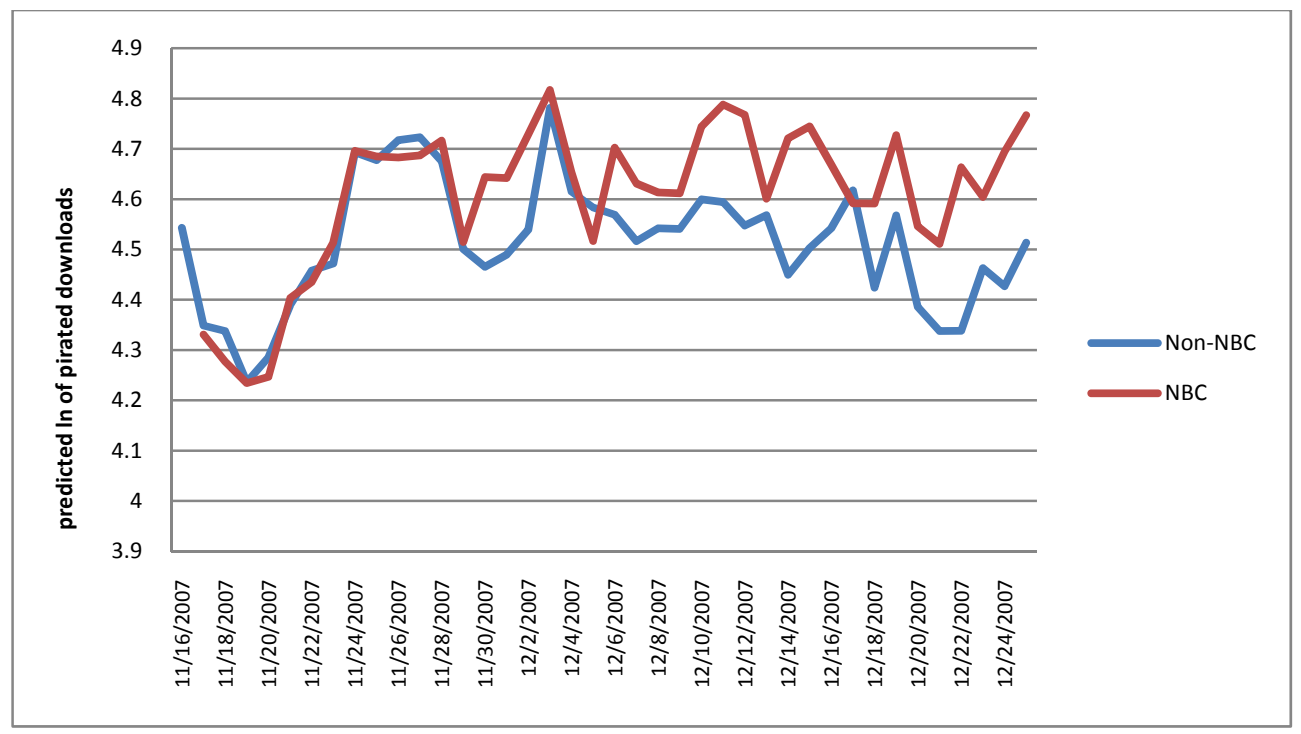

If non-NBC piracy is a good control for NBC piracy, then we would expect $\gamma_{t}$ to be equal to 0 for all dates before the treatment. One can see from the chart above that non-NBC piracy tracks NBC quite well until November $30^{\text {th }}$, which is the first date that NBC began removing their 
episodes from iTunes. More formally, a Wald test of the null hypothesis that all $\gamma_{t}$ are jointly equal to zero for all $t$ before Devember 1 could not be rejected at the 5, 10, or even $20 \%$ levels. Conversely, it is quite clear from the graph that NBC piracy increases beyond non-NBC piracy immediately following the removal from iTunes and, for all but a few dates, remains at this increased level for the 25 days following the removal of NBC content from iTunes. The tstatistics for nearly all $\gamma_{\mathrm{t}}$ for times after December 1 indicates that the difference between NBC piracy and non-NBC piracy is significant at the 5\% level and suggesting that NBC piracy increased significantly relative to non-NBC piracy after iTunes removal.

While the regression and chart above provide strong evidence that the removal of the digital distribution channel increased piracy — and that this increase was maintained for at least the time period of our data - it does not conveniently allow us to measure the overall average increase in piracy caused by the event. To avoid holiday effects, we use data from Nov 18 to December 15 which gives us two weeks before and two weeks after the event. Given this, next we run the following regression as standard difference-in-difference model to estimate the aggregate effect of the removal of NBC content from iTunes:

$$
\log \left(\text { downloads }_{i t}\right)=\alpha_{i}+\beta D_{t}+\gamma N B C_{i} * D_{t}+\varepsilon_{i t}
$$

These models are similar to model (2) above, except that here $D_{t}$ is a single indicator variable equal to 1 if the observation occurs in the two weeks after December 1, 2007 and equal to 0 if it is in the two weeks before. Thus $\gamma$ captures the average effect of the event on NBC's piracy relative to control group's piracy. A positive value indicates that NBC piracy has increased by about $100 * \gamma$ percent in the period after removal, relative the piracy of non-NBC channels. As

\footnotetext{
12 Observations occurring on December 1 are removed from the data as NBC was in the process of removing episodes on this date. Including these observations would not materially impact our results.
} 
before, we include episode level fixed effects in the form of $\alpha_{i}$ and daily level fixed effects in the form of $D_{t}$. We also estimate a specification with date fixed effects where we use a dummy for each day similar to (2).

We use a log specification of our dependent variable for several reasons. First, the download data is heavily skewed and hence log transformation provides a better fit. ${ }^{13}$ Second, previous papers have extensively used log specifications for album sale and piracy (e.g. Hendrics and Sorensen 2009). Third, a log specification accounts for nonlinearity in the treatment effect. For example, piracy and sales changes may be particularly large for popular episodes, and log specification will capture some of this nonlinearity.

However, by taking logarithms, we implicitly assume that the effect of the removal of the digital distribution channel is proportional. In a linear model, a few large episodes can have significant effect on our result. Thus, while most of the episodes may show a large proportional increase in piracy, if a few large ones do not increase enough, a linear specification estimates will differ from the log specification. Given the fit of our data and based on prior literature, we use log transformation as our primary specification. However, we also estimate a linear specification, and find that our results are robust to using a linear specification (results discussed in more detail below and in footnote 16).

One might worry that downloads of episodes within a season or series may be correlated. For example, an increase in piracy of episode 1 of Heroes season 1 may be correlated with episode 12 of Heroes season 2. Therefore, following Bertrand, Duflo, and Mullainathan (2004), we cluster our standard errors at the series level, which allows all episodes within our 76 unique

\footnotetext{
${ }^{13}$ We also ran a Box-Cox test on the model to determine the best fitting transformation of downloads - the test produced a $\theta=.04$, indicating quite strongly that the log transformation produces the best fit to our data.
} 
series to be correlated. We also estimate robust standard errors to allow for heterogeneity across series.

The results of model 3 are displayed in columns (i) and (ii) of Table 2. Column (i) reports results for model 3, while column (ii) adds date fixed effects, producing very similar results. The variable of interest in the regression is $\gamma$ as it indicates the percentage change in pirated downloads for NBC over and above any change for non-NBC programs.

The coefficients from the regressions in columns (i) and (ii) show that while non-NBC piracy increased by $5.8 \%$ during this time period, NBC piracy increased by an additional $11.4 \%$ over and above this level. Thus, the removal of NBC content from iTunes caused an $11.4 \%$ increase in piracy over and above the change in the non-NBC "control group." This shows a significant substitution between legitimate digital distribution and piracy channels. Based on $95 \%$ confidence intervals computed using the clustered standard errors, the removal of NBC's iTunes channel caused an increase in piracy between $3.4 \%$ and $19.4 \%$.

Table 2: OLS Regressions of Log of Daily Downloads November 18 - December 15, 2007 and 2008

\begin{tabular}{|c|c|c|c|c|}
\hline & \multicolumn{2}{|c|}{2007} & \multicolumn{2}{|c|}{2008} \\
\hline & (i) & (ii) & (iii) & (iv) \\
\hline After $12 / 1$ & $\begin{array}{c}0.058^{\dagger} \\
(0.029)\end{array}$ & & $\begin{array}{l}0.337^{* *} \\
(0.029)\end{array}$ & \\
\hline After $12 / 1 *$ & $0.114^{* *}$ & $0.115^{* *}$ & -0.055 & -0.052 \\
\hline Removed & $(0.041)$ & $(0.041)$ & $(0.058)$ & $(0.059)$ \\
\hline Constant & $4.513^{*}$ & $4.314^{*}$ & $4.296^{*}$ & $3.806^{*}$ \\
\hline & $(0.011)$ & $(0.027)$ & $(0.013)$ & $(0.109)$ \\
\hline Date Fixed Effects & $\mathrm{No}$ & Yes & No & Yes \\
\hline \# of Episodes & 6,005 & 6,005 & 6,376 & 6,376 \\
\hline Observations & 161,784 & 161,784 & 170,556 & 170,556 \\
\hline $\mathrm{R}^{2}$ & 0.028 & 0.16 & 0.15 & 0.37 \\
\hline
\end{tabular}

The dependent variable is $\ln$ (total pirated downloads before/after September 9. Tstatistics are listed in parenthesis; ${ }^{* *},{ }^{*}$, and ${ }^{\dagger}$ denote significance at $0.01,0.05$, and 0.10 respectively. Regressions include episode level fixed effects with standard errors clustered at the series level. 
In columns (iii) and (iv) we run the same models for the same time period but for the later year in 2008 (November 18 through December 15, 2008), when there was no event or treatment at iTunes. ${ }^{14}$ In these regressions, $\gamma$ is negative and insignificant, indicating that the increase in NBC piracy over and above non-NBC piracy is not somehow typical during this time of year further evidence of a causal relationship between the 2007 increase and the removal of NBC content from iTunes.

The increase in non-NBC piracy observed here could, however, derive from some other outside factor or be a general time trend for all piracy during this period, in which case the difference in difference model is an accurate estimation of the effect on NBC piracy. However, we have not been able to determine any outside factors during this timeframe that might result in an increase in television piracy demand unrelated to NBC's iTunes decision.

An alternate explanation, and one that derives from the theory section, is that removing the digital distribution channel could have a spillover effect if the non-financial cost of piracy is largely fixed. Thus the 5.8\% increase in non-NBC piracy found in column (i) could be a result of the December $1 \mathrm{NBC}$ treatment and not a general time trend. If this were the case, then our results would understate the displacement of piracy by the iTunes channel, because the change in non-NBC piracy would no longer be an appropriate counterfactual to predict what should have happened to NBC piracy in the absence of the December 1 event. However, while the evidence is consistent with the possibility of a spillover effect, this study cannot identify this effect precisely due to lack of an appropriate counterfactual. In fact, the results above show a significant increase in non-NBC piracy during the same time period in 2008. As well, a linear specification for the

\footnotetext{
${ }^{14}$ In the 2008 regression there were about 370 more episodes available for analysis than in the 2007 regression (in part due to the additional NBC episodes that appeared after 12/1/2009. However, removing these new episodes from the 2008 analysis produces no material changes to our results.
} 
2007 event shows a small decrease in non-NBC piracy, because a few extremely popular nonNBC episodes experienced large decreases in piracy (while the majority of non-NBC episodes experienced an increase).

\section{Table 3: OLS Regressions of Log of Daily Downloads by Genre November 18 - December 15, 2007}

\begin{tabular}{|c|c|c|c|c|}
\hline & Drama & Action & Comedy & $\overline{S c i-F i}$ \\
\hline $\begin{array}{l}\text { After } 12 / 1 * \\
\text { NBC }\end{array}$ & $\begin{array}{r}0.011 \\
(0.062)\end{array}$ & $\begin{array}{l}0.112 \dagger \\
(0.060)\end{array}$ & $\begin{array}{l}0.223^{*} \\
(0.092)\end{array}$ & $\begin{array}{r}0.213^{*} \\
(0.064)\end{array}$ \\
\hline Constant & $\begin{array}{l}5.050^{* *} \\
(0.049)\end{array}$ & $\begin{array}{l}3.704^{* *} \\
(0.055)\end{array}$ & $\begin{array}{c}4.920^{* *} \\
-0.029\end{array}$ & $\begin{array}{l}4.210^{* *} \\
(0.076)\end{array}$ \\
\hline Observations & 27,378 & 51,830 & 40,734 & 11,738 \\
\hline $\begin{array}{l}\text { \# number of } \\
\text { episodes }\end{array}$ & 1014 & 1925 & 1510 & 435 \\
\hline $\mathrm{R}^{2}$ & 0.21 & 0.24 & 0.20 & 0.27 \\
\hline
\end{tabular}

The dependent variable is $\ln$ (total pirated daily downloads). T-statistics are listed in parenthesis; **, *, and $\dagger$ denote significance at $0.01,0.05$, and 0.10 respectively. Includes both episode and date fixed effects, with standard errors clustered by series. 15

To explore the source of the increase in NBC piracy, in Table 3 we break down our results by type of program and run model (3) for four separate genre groups: Drama, Action, Comedy, and Science Fiction. Conventional wisdom suggests that comedy, sci-fi and action programming appeals more to a younger demographic. ${ }^{16}$ It is well known that this younger demographic is also more likely to indulge in piracy (Liebowitz 2007). Consistent with this conjecture, our results show that the increase in piracy for comedy and sci-fi is above $20 \%$, for action the increase is

\footnotetext{
${ }^{15}$ For this analysis, we dropped several shows/episodes that did not fit into these four major categories.

${ }^{16}$ For example, see this Nielsen June 2009 report with respect to genre preferences in media consumption for teens (http://www.scribd.com/doc/20127220/Nielsen-Report-How-Teens-Use-Media-June2009, accessed May 3, 2010) and this Time Warner report on media advertising targeting to young males (http://www.cablemediasales.com/pages/nets/?cp=nets\&sp=demo\&demo=M18-49, accessed May 3, 2010).
} 
about $11 \%$ and the piracy increase for drama programming is only slightly positive and insignificant.

Returning to our main results in model (3), we note that there are a few ways to interpret the overall percentage change in piracy resulting from the removal of iTunes content. The first is to calculate the implied average unit increase in piracy per episode as the average number of pirated NBC downloads per episode prior to December 1 (237) multiplied by the estimated increase in piracy in our model (11.4\%) to obtain an average increase of 27 pirated downloads per episode attributable to NBC's decision to remove the iTunes distribution channel. ${ }^{17}$ Since there were 1,683 NBC episodes available for piracy prior to December 1 and the average episode experienced an increase of 27 pirated downloads, using this method we would conclude that the removal of NBC content from iTunes caused a total increase of about 48,000 pirated downloads per day of NBC content. The $95 \%$ confidence interval around this number is 13,500 to 77,400 pirated downloads per day.

Another way to look at this increase is to compare it to iTunes purchases of NBC episodes before the removal of the content. To do this, we were able to obtain data showing that NBC sold slightly over 320,000 episodes of its content through iTunes in the two weeks prior to December 1, 2007, or about 23,000 episodes per day. Thus, our results suggest that the unit increase in piracy was about twice as large as the pre-removal sales on iTunes. ${ }^{18}$ This result, while

\footnotetext{
${ }^{17}$ While we have explained why the log model is the appropriate specification here, we also tested a linear model. The coefficient on the interaction term between NBC and the after 12/1 dummy in the linear model is about 25 downloads per day and is significant at the $95 \%$ level. Thus for our coefficient of interest, a linear model produces results similar to those implied by our log model (a unit increase of 25 versus an increase of 27 for the $\log$ model).

${ }^{18}$ Although notably, at the $95 \%$ confidence level we cannot reject the null hypothesis that the increase in pirated downloads was less than the size of the NBC iTunes market before it was removed. This is primarily due to the large standard errors that result from clustering at the series level, as we only observe 88 unique television series in our data.
} 
surprising at first, was predicted in our theory section if the fixed cost of piracy were significant. We discuss this in further detail in the final section of the paper.

Importantly, our model is measuring the increase in piracy across episodes in percentage terms. One practical question is whether or not the percentage increase that we've witnessed is being driven disproportionately by the most or least popular episodes. To investigate this, we first separated out the top $20 \%$ most downloaded episodes (the "head") from the remaining episodes (the "tail"). ${ }^{19}$ Using this split, we ran a triple difference model, to examine if the increase in NBC piracy, over and above non-NBC piracy, was different for the head (the most popular $20 \%$ of episodes) than for the tail (the remaining $80 \%$ ).

$\log \left(\right.$ downloads $\left._{i t}\right)=\alpha_{i}+\beta D_{t}+\gamma N B C_{i} * D_{t}+\delta D_{t} *$ Head $_{i}+v D_{t} *$ Head $_{i}^{*} N B C_{i}+\varepsilon_{i t}$

In model $4, D_{t}$ is again a dummy variable equal to 1 if the date is after December 1 , and $\mathrm{Head}_{i}$ is now a dummy variable indicating if the episode is in top $20 \%$ in terms of number of downloads. Thus, $\gamma$ represents the increase in piracy caused by NBC's removal from iTunes for the less popular tail episodes, while $\gamma+v$ indicates the increase in piracy for the most popular episodes. ${ }^{20}$

The results in Table 4 suggest that on a percentage basis the change in piracy for the most popular episodes in the "head" was statistically no different than that for the "tail." However, we also note that interpreting these percentage results in light of the unit downloads of head and tail titles on both iTunes and through piracy suggests that iTunes downloads for head titles were far more likely to convert to piracy than iTunes downloads of tail titles were.

\footnotetext{
${ }^{19}$ Our classification follows the widely used "80/20" Pareto principle; though a 90/10 or 70/30 split yields similar results.

${ }^{20}$ As before, several main effects and pairwise combinations of these effects have been left out of the model as they would be subsumed by the episode and date fixed effects.
} 
Table 4: Analysis of Piracy Change for Head and Tail Titles

\begin{tabular}{l|c}
\hline & DVD Box Sets \\
\hline After 12/1 & $0.086^{*}(0.034)$ \\
After 12/1 NBC & $0.104^{* *}(0.0424)$ \\
After 12/1 * Head & $-0.110^{*}(-0.044)$ \\
After 12/1 * Head * NBC & $-0.039(0.069)$ \\
Constant & $4.518^{*}(-0.010)$ \\
\hline Observations & 161,784 \\
\# of episodes & 6,005 \\
$\mathrm{R}^{2}$ & 0.35 \\
\hline The dependent variable is ln(iTunes Downloads). \\
tstatistics are listed in parenthesis; ${ }^{* *}$ and ${ }^{*}$ denote \\
significance at 0.01 and 0.05 respectively. Regressions \\
include episode-level fixed effects with standard errors \\
clustered at the series level.
\end{tabular}

This finding also sheds light on the fixed versus variable cost to piracy arguments outlined in the theory section. Specifically, in the results above, our primary argument for a fixed cost to piracy is the fact that the increase in piracy caused by the removal of the iTunes channel was larger than the size of the iTunes market, pre-removal. A possible objection to this is a story of variable cost: when the iTunes channel is removed, some percentage of iTunes customers turn to piracy. Based on how the BitTorrent protocol works, this additional demand becomes supply and makes download speeds faster, reducing the variable cost of downloading and attracting additional new pirates (who may not have even been iTunes customers).

However, because of the nature of the number of connections maintained in BitTorrent "swarms," episodes with a small number of downloaders will experience a much larger reduction in variable costs (increase in download speeds) from additional downloaders than episodes with a large number of downloaders will. Therefore, if decreasing variable cost is causing the increase in piracy, we would expect to observe this phenomenon most strongly among less popular episodes. . However, this is in contrast to what we observe that, if anything, the increase in piracy for the most popular "head" shows was larger than the size of the iTunes market for these shows. 
To close, we note that the main results reported throughout this section are robust to a variety of alternative specifications. A linear model also shows a similarly sized increase in NBC piracy over and above non-NBC piracy. Changes to the time frame, the removal of the Sci-Fi and USA networks from the analysis, and the inclusion of controls for the age of each episode do not materially impact the results. Coding November 30 as the first day of the "after removal from iTunes" period produces even stronger results, likely because NBC started removing content on November 30. Additionally, one might worry that the early announcement of NBC's removal from iTunes (announced several months before it happened) might have caused people to switch to piracy before the actual removal. If this were the case, piracy would have spiked before December 1 causing our results to underestimate the true effect. Thus, the model appears to produce robust, and if anything somewhat conservative, results.

\subsection{Impact on Amazon.com DVD Box Set Sales}

To determine the degree to which the iTunes digital distribution channel displaces purchases of DVD box sets sold on the Internet, we employ similar tests to those above. The dependent variable in this case is the Amazon.com sales rank, and thus a decrease in a DVD's rank indicates an increase in sales of that DVD. Table 5 compares means for sales ranks of NBC and non-NBC box sets before and after December 1, 2007.

Table 5: DVD Sales Rank at Amazon.com (Comparison of Means) November 11 - December 15, 2007

\begin{tabular}{l|rc}
\hline & NBC Networks & Non-NBC Networks \\
\hline Amazon.com sales rank prior to Dec. 1 & 24,553 & 35,384 \\
Amazon.com sales rank after Dec. 1 & 26,056 & 38.785 \\
Change & 1,503 & 3,401 \\
& $6 \%$ & $10 \%$ \\
\hline
\end{tabular}

We see from this table that the mean rank for non-NBC box sets increased by $10 \%$, meaning that fewer non-NBC television series box sets were sold after December 1 than before. The increase 
in rank for NBC box sets was only $6 \%$, which could indicate that the removal of NBC content from iTunes caused some additional purchases of DVD box sets. However, as with our analysis for piracy, this comparison of means does not account for changes in price that may occur during this time period (especially with the approaching holidays), nor is a linear model appropriate when predicting sales rank due to the Pareto distribution of sales across box sets. Thus, we run a similar difference-in-difference model to the one we ran for piracy, specified as follows:

$$
\ln \operatorname{Rank}_{i t}=\mu_{i}+\alpha D_{t}+\beta N B C_{i} * D_{t}+\delta \log \left(P_{i t}\right)+\varepsilon_{i t}
$$

where $\operatorname{Rank}_{i t}$ is defined as the Amazon.com sales rank of season box set $i$ on day $t$. $D_{t}$ is an indicator variable equal to one in the 2-week period after December 1, $P_{i t}$ is the price of box set $i$ on day $t$ and $\mu_{i}$ is a vector of fixed effects for each season box set. We log transform the Amazon sales rank as well as the daily Amazon price consistent with prior literature and based on the explanation provided in the data section. As above, our regressions are conducted on a balanced sample of titles. Indeed we do not observe any new DVD box set titles added during this timeframe. ${ }^{21}$

One may worry that NBC (or Amazon) may change prices of NBC DVDs in response to the event. Our data does not show any unusual price changes for NBC DVDs. We also had a discussion with $\mathrm{NBC}$ and do not believe NBC strategically changed the prices. However, inclusion of price data provides a good control for our key estimate $\beta$. Omission of pricing information may lead to omitted variable bias. We present results for this regression in Table 6 .

\footnotetext{
${ }^{21}$ Discussions with knowledgeable persons in the television industry suggest that almost all DVD box sets are released immediately before the fall television season, which starts in September.
} 


\section{Table 6: OLS Regressions of Ln Sales Rank of Season DVD Box Sets November 18 - December 15, 2007}

\begin{tabular}{l|c}
\hline & DVD Box Sets \\
\hline Ln(Amazon Price) & $* * 1.727(0.103)$ \\
After $12 / 1$ & $-0.023(0.020)$ \\
After $12 / 1 *$ NBC & $0.000(0.048)$ \\
Constant & $2.925(0.338)$ \\
\hline Observations & 9555 \\
\# number of unique & 397 \\
DVD box sets & 0.29 \\
$\mathrm{R}^{2}$ & \\
\hline The dependent variable is $\ln ($ Amazon \\
sales rank). T-statistics are listed in \\
parenthesis; ${ }^{* *}$ and ${ }^{*}$ denote significance at \\
0.01 and 0.05 respectively. Regressions \\
include DVD-level fixed effects. Adding \\
date fixed effects does not materially \\
change the results.
\end{tabular}

We note that raising price has the predicted effect of decreasing sales, as observed by increased rank. We also observe no significant change in sales rank for NBC box sets relative to non-NBC box sets after December 1. Thus, the removal of the digital sales channel did not seem to increase sales of DVD box sets sold on the Internet. ${ }^{22}$ Given the prior marketing literature on channel differentiation (e.g. Viswanathan 2005), this finding could suggest that consumers consider illegal digital downloads a much stronger substitute for legal digital downloads than legal physical purchases are for legal digital downloads. We discuss this result in more detail below.

\subsection{NBC's Return to iTunes}

The results presented above represent the best experiment we can find to determine the relationship between piracy, digital distribution, and physical sales. However, another experiment occurred on September 9, 2008 when, after reaching an agreement with Apple, NBC restored all of their content to the iTunes store. Unfortunately, this date also coincides with the

\footnotetext{
${ }^{22}$ We analyzed DVD box sets at the level of box set sales per day, because price is a significant predictor of sales and changes by box set and by the day. However, if we were to cluster our standard errors at the series level, it would merely inflate them and thus our results would remain close to zero and insignificant.
} 
new fall season of television in 2008, which presents complications for our empirical analysis. The premiere of a new season of television undoubtedly increases demand for older seasons of the same show, causing large day-to-day swings in piracy of older content that correspond to the premieres of new shows and increasing the noise in the data around this period (as evidenced in the large standard errors and low explanatory power reported in Table 7 below).

However, it still may be valuable to examine the changes in piracy around this time period to see if our earlier findings are supported. In Section 5.1 we noted that when NBC removed their content from iTunes, NBC pirated downloads increased by more than the number of iTunes purchases previously made, and we interpreted this as evidence of a fixed cost to piracy. If the non-financial cost of piracy is largely fixed, then we would not expect to see as many customers return to iTunes as left when the content becomes available again there.

To explore this possibility we run model 3 again for the 4 weeks surrounding September 9, 2008, reporting these results in Table 7. Our results suggest that when NBC content was returned to iTunes, piracy of NBC content was reduced by $7.7 \%$ over and above any change for non-NBC. However, this result is statistically insignificant, and considering the point estimate alone suggests that the unit decrease in piracy when NBC returned to iTunes is much smaller than the unit increase in piracy when NBC left iTunes. 
Table 7: OLS Regressions of Log of Daily Downloads

August 26 - September 22, 2008

\begin{tabular}{l|rr}
\hline & (i) & (ii) \\
\hline After 12/1 & 0.063 & \\
& $(0.049)$ & \\
After $12 / 1 * \mathrm{NBC}$ & -0.077 & -0.077 \\
& $(0.096)$ & $(0.096)$ \\
Constant & 4.306 & 4.275 \\
& $(0.021)$ & $(0.053)$ \\
\hline Date Fixed Effects & No & Yes \\
\hline Observations & 129,720 & 129,720 \\
Number of episodes & 4,709 & 4,709 \\
$\mathrm{R}^{2}$ & 0.015 & 0.074 \\
\hline
\end{tabular}

The dependent variable is $\ln ($ total pirated downloads before/after September 9. T-statistics are listed in parenthesis; ${ }^{* *},{ }^{*}$, and ${ }^{\dagger}$ denote significance at $0.01,0.05$, and 0.10 respectively. Standard errors are clustered at the series level.

\section{Discussion}

Our results represent the first test we are aware of that quantifies the effect of a legal digital distribution channel on both online piracy and online sales of physical products. As such, they offer decision-makers at media firms some much-needed evidence regarding the ability of legal digital distribution channels to compete with illegal piracy channels without cannibalizing physical distribution channels.

Specifically, in this study, we used NBC's decision to remove its content from the iTunes music store on December 1, 2007 as a quasi experiment and found that the removal of NBC's primary digital sales channel caused an $11.4 \%$ increase in piracy of that content over and above any change experienced by competitor networks $\mathrm{ABC}, \mathrm{CBS}$, and Fox over the same period. An $11.4 \%$ increase in piracy corresponds to about 27 more downloads per day per episode, or 48,000 additional pirated downloads of all NBC content per day. To put this number in perspective, it is about twice as large as the number of daily iTunes sales NBC received in the two weeks before December 1 . This estimate is conservative due to the fact that Mininova piracy, while arguably a 
good proxy for overall BitTorrent piracy, represents only a portion of overall BitTorrent television piracy.

We note that this large jump in piracy (larger than the size of the iTunes market) is consistentwith there being a significant fixed cost to piracy. In other words, our results are consistent with the possibility that iTunes purchasers may avoid piracy because the fixed cost to learn to use BitTorrent (or the fixed moral/stigma cost of illegal behavior) makes piracy less attractive than legitimate purchases through iTunes. However, when the digital sales channel is not available, these individuals turn to piracy, pay the fixed cost and, owing to the seemingly low marginal costs of additional downloads, begin to consume more content through piracy than they had previously purchased. Moreover, this phenomenon seems most prevalent for the most popular episodes of television, which suggests that it is not driven by a decrease in the variable cost of piracy driven by more pirates participating in the BitTorrent swarm.

We note that a fixed cost effect could even have a spillover effect for other networks that have a digital sales channel, since once the fixed cost is paid for NBC it is likely paid for, say, $\mathrm{ABC}$ as well. Our results are consistent with this possibility — the model shows a 5.8\% increase in nonNBC piracy when we might have expected a decrease due to decreasing interest. However, this result should be treated cautiously owing to a lack of strong counter-factual evidence for nonNBC piracy. Either way, these results should sound an alarm to content providers, because once the fixed cost of piracy is sunk it may be difficult to get pirates to return to legal options. Indeed, while the return of $\mathrm{NBC}$ content to iTunes presented some analytical challenges due to coinciding with the start of the fall television season, we observed a smaller and statistically insignificant decrease in piracy for NBC content (as compared to non-NBC content) when it was returned to iTunes. 
Digital distribution's impact on sales of DVD box sets sold through Internet channels presents a different story, however. When NBC removed their archived seasons of television from iTunes, we found no significant change in the Amazon.com sales rank for NBC's DVD sales relative to the trend that we saw for non-NBC box sets. One possible interpretation of this finding is that digital downloads and DVD's are not substitutes in the short term, and thus adding a digital distribution channel does not lead to a short-term displacement in DVD box set sales. A similar interpretation is that there is a fixed cost to digital viewing of television, and once a consumer has "gone digital" she is unlikely to come back.

We note that there are several limitations to our study. First, and most notably, our findings represent a test of short-term elasticity between legitimate digital distribution, pirated digital distribution, and physical distribution channels. The long-term presence of a digital distribution channel likely has a much stronger effect on physical channel sales than those observed here in the short term. However, it is important to note that there is little that media firms can do to forestall the penetration of digital channels given the increased ease, speed, and flexibility associated with obtaining media in digital environments. Rather, our results suggest that media companies would be best served by competing with piracy through digital distribution rather than hoping that the lack of a legitimate digital distribution channel will drive consumers away from the digital channel and back to physical purchases. In addition to this limitation, we also note that the spillover results mentioned above should be interpreted cautiously owing to the lack of an appropriate counterfactual. Further, we note that our results represent a snapshot in time for a single media type. It would be useful for future studies to analyze competition between legitimate and illegitimate digital channels in other settings to confirm our results. 
Another interesting potential direction for future research relates to the "moral" cost of piracy. In the theory section, we argued that the decision to purchase or pirate rests largely on the shape of the non-financial cost curve associated with piracy. While part of that cost may be related to learning or to the (sometimes) diminished quality of the pirated copies, these costs may approach zero in the future as pirates become more sophisticated in their methods, consumers become more technologically savvy, and client software for piracy becomes even more user-friendly. We suspect that a large part of antipiracy efforts in the future may need to rely on the consumer's "moral" cost associated with piracy. In order to price competitively, digital distribution efforts would benefit from knowing more about the shape of this moral cost. As such, we believe that user studies — whether in the laboratory or in the field — aimed at revealing the nature of the moral cost of piracy for different types of consumers is a fertile area for future research. 


\section{References}

Arango, T. 2006. Retail-iation. New York Post, September 22, page 31.

Balasubramanian, S. 1998. Mail versus Mall: A Strategic Analysis of Competition between Direct Marketers and Conventional Retailers. Marketing Science, 17(3) 181-195.

Bertrand, M, E. Duflo, S. Mullainathan. 2004. How Much Should We Trust Differences-inDifferences Estimates? The Quarterly Journal of Economics, 119(1) 249-275.

Bhattacharjee, S., R. Gopal, K Lertwachara, J. Marsden, R. Telang. 2008. The Effect of Digital Sharing Technologies on Music Markets: A Survival Analysis of Albums on Ranking Charts. Management Science, 53(10) 1359-1374.

Biyalogorsky, E., P. Naik. 2003. Clicks and Mortar:The Effect of On-line Activities on Off-line Sales. Marketing Letters, 14(1) 21-32.

Blackburn, D. 2004. “On-line Piracy and Recorded Music Sales,” Harvard University, Unpublished Manuscript.

Brynjolfsson, E., Y. Hu, M. Smith. 2003. Consumer Surplus in the Digital Economy: Estimating the Value of Increased Product Variety. Management Science, 49(11) 1580-1596.

Chevalier, J., A. Goolsbee. 2003. Measuring prices and price competition online: Amazon.com and BarnesandNoble.com. Quantitative Marking and Economics, 1(2) 203-222.

Chiang, W. Y., D. Chajed, J.D. Hess. 2002. Direct marketing, indirect profits: A strategic analysis of dual-channel supply-chain design. Management Science, 49(1) 1-20.

Christin, N., A. Weigend, J. Chuang. 2005. Content Availability, Pollution, and Poisoning in File Sharing Peer-to-Peer Networks. Proceedings of the 6th ACM conference on Electronic commerce, pp. 68-77.

Chu, J., P.K. Chintagunta, N. Vilcassim. 2007. Assessing the Economic Value of Distribution Channels - An Application to the PC Industry. Journal of Marketing Research, 44(1) 29-41.

Danaher, B., J. Waldfogel. 2008. Reel Piracy: The Effect of Online Movie Piracy on Film Box Office Sales. Working paper. University of Pennsylvania, Philadelphia, Pennsylvania.

Deleersnyder, B., I. Geyskens, K. Gielens, M.G. Dekimpe. 2002. How Cannibalistic is the Internet Channel? A study of the newspaper industry in the United Kingdom and The Netherlands. International Journal of Research in Marketing 19(4) 337-348.

DVD News. 2006. Top DVD Retailers: Market Shares. DVD News Magazine 10(41), November 30. 
Friedman, L. G., Furey, T. R. 1999. The Channel Advantage: Going to Market with Multiple Sales Channels to Reach More Customers, Sell More Products, Make More Profit. Oxford ; Boston Butterworth-Heinemann.

Ghose A., M D Smith, R Telang R. 2006. Internet Exchanges for Used Books: An Empirical Analysis of Product Cannibalization and Welfare Impact. Information Systems Research, 17(1), 3-19.

Goodell, J. 2003. Steve Jobs: The Rolling Stone Interview. Rolling Stone Magazine. Available from: http://www.rollingstone.com/news/story/5939600/steve_jobs_the_rolling_stone_interview. Last accessed March 15, 2009.

Hendricks, K., A. Sorensen. 2009. Information and the Skewness of Music Sales. Journal of Political Economy, 117(2), 324-369.

Hui, K., I. Png. 2003. Piracy and the Legitimate Demand for Recorded Music. Contributions to Economic Analysis and Policy, 2(1).

Jain, S. 2008. Digital Piracy: A Competitive Analysis. Marketing Science 27(4) 61-626.

Jeuland, A.P., S.M. Shugan. 1983. Managing Channel Profits. Marketing Science 2(3) 239-272.

McBride, S., M. Marr. 2006. Target, a Big DVD Seller, Warns Studios Over Download Pricing. The Wall Street Journal, Page A1, October 9.

Menn, J. 2006. Target, Disney in DVD Truce. The Los Angeles Times, November 18.

Nagin, D.S., R. Paternoster. 1991. On the Relationship of Past To Future Participation in Delinquency. Criminology, 29(2) 163-189.

Netherby, J. 2005. Amazon.com Dominates in Online DVD Sales. Reed Business Information Inc. Gale Group, Farmington Hills, Michigan, December 19.

Oberholzer, F., K. Strumpf. 2007. The Effect of File Sharing on Record Sales. An Empirical Analysis. Journal of Political Economy, 115(1) 1-42.

Peitz, M, P. Waelbroeck. 2004. The Effect of Internet Piracy on Music Sales: Cross-Section Evidence. Review of Economic Research on Copyright Issues, 1(2) 71-79.

Rob, R., J. Waldfogel. 2006. Piracy on the High C's: Music Downloading, Sales Displacement, and Social Welfare in a Sample of College Students. Journal of Law and Economics, 49(1) 2962.

Rob, R., J. Waldfogel. 2007. Piracy on the Silver Screen. Journal of Industrial Economics, 55(3) 379-393.

Sinha, R.K., F. Machado, C. Sellman. 2010. Don't Think Twice, It's All Right: Music Piracy and Pricing in a DRM-Free Environment. Journal of Marketing, 74(2) 40-54. 
Smith, Michael D., Rahul Telang. 2008. Internet Exchanges for Used Digital Goods. Working Paper. Carnegie Mellon University, Pittsburgh, Pennsylvania.

Smith, M., R. Telang. 2009. Competing with Free: The Impact of Movie Broadcasts on DVD Sales and Internet Piracy. Management Information Systems Quarterly, 33(2) 312-338.

Thompson, A. 2003. Tinseltown Follies. The New York Magazine. May 5.

Vernik, D. 2009. Digital Music Set Free: The Flip Side of DRM. Working Paper. Rice University, Houston, Texas.

Viswanathan, S. 2005. Competing Across Technology-Differentiated Channels: The Impact of Network Externalities and Switching Costs. Management Science, 51(3) 483-496.

Waldfogel, J. 2007. Lost on the web: Does Web Distribution Stimulate or Depress Television Viewing? Working Paper. University of Pennsylvania, Philadelphia, Pennsylvania.

Webb, K. L. 2002. Managing channels of distribution in the age of electronic commerce. Industrial Marketing Management, 31(2) 95-102.

Zentner, A. 2005. File Sharing and International Sales of Copyrighted Music: An Empirical Analysis with a Panel of Countries. Topics in Economic Analysis \& Policy 5(1), Article 21. Available at: http://www.bepress.com/bejeap/topics/vol5/iss1/art21. 